\title{
Amphiphysin is necessary for organization of the excitation- contraction coupling machinery of muscles, but not for synaptic vesicle endocytosis in Drosophila
}

\author{
Azam Razzaq, ${ }^{1,2}$ Iain M. Robinson, ${ }^{1}$ Harvey T. McMahon, ${ }^{3}$ Jeremy N. Skepper, ${ }^{4}$ Ya Su, ${ }^{1,7}$ \\ Andrew C. Zelhof, ${ }^{5,6}$ Antony P. Jackson, ${ }^{2}$ Nicholas J. Gay, ${ }^{2}$ and Cahir J. O'Kane ${ }^{1,8}$ \\ ${ }^{1}$ Department of Genetics, University of Cambridge, Cambridge CB2 3EH, UK; ${ }^{2}$ Department of Biochemistry, University \\ of Cambridge, Cambridge CB2 1QW, UK; ${ }^{3}$ Medical Research Council Laboratory of Molecular Biology, Cambridge CB2 \\ 2QH, UK; ${ }^{4}$ Multi-Imaging Centre, Department of Anatomy, University of Cambridge, Cambridge CB2 3DY, UK; ${ }^{5}$ Institute \\ of Neuroscience and Institute of Molecular Biology, Howard Hughes Medical Institution, University of Oregon, Eugene, \\ Oregon 97403, USA; ${ }^{6}$ Department of Biology, Howard Hughes Medical Institution, University of California, \\ San Diego, La Jolla, California 92093, USA
}

\begin{abstract}
Amphiphysins 1 and 2 are enriched in the mammalian brain and are proposed to recruit dynamin to sites of endocytosis. Shorter amphiphysin 2 splice variants are also found ubiquitously, with an enrichment in skeletal muscle. At the Drosophila larval neuromuscular junction, amphiphysin is localized postsynaptically and amphiphysin mutants have no major defects in neurotransmission; they are also viable, but flightless. Like mammalian amphiphysin 2 in muscles, Drosophila amphiphysin does not bind clathrin, but can tubulate lipids and is localized on T-tubules. Amphiphysin mutants have a novel phenotype, a severely disorganized T-tubule/sarcoplasmic reticulum system. We therefore propose that muscle amphiphysin is not involved in clathrin-mediated endocytosis, but in the structural organization of the membrane-bound compartments of the excitation-contraction coupling machinery of muscles.
\end{abstract}

[Key Words: Dynamin; DLG; indirect flight muscles; T-tubules; ryanodine receptor; myopathy]

Received May 10, 2001; revised version accepted September 20, 2001.

Clathrin-mediated endocytosis is a process by which cells retrieve proteins from the plasma membrane into vesicles. It is also a major mechanism for retrieval of synaptic vesicle components after exocytosis. During this process, areas of membrane containing proteins to be endocytosed are folded inward to form a pit; the pit then closes up, generating a vesicle that breaks off from the membrane. Dynamin is essential for the scission of these nascent vesicles, providing the mechanical force, and considerable evidence suggests that amphiphysin is essential for the recruitment of dynamin to its site of action (Takei et al. 1999; Vallis et al. 1999).

Two amphiphysin genes (1 and 2) are found in mammals (Lichte et al. 1992; Ramjaun et al. 1997; Wigge et al. 1997a). Amphiphysin 1 is highly brain-enriched, as are the larger splice variants of amphiphysin 2 . The $\mathrm{N}$ ter-

\footnotetext{
${ }^{7}$ Present address: Cambridge Institute for Medical Research, University of Cambridge, Addenbrooke's Hospital Site, Hills Road, Cambridge CB2 2XY, UK.

${ }^{8}$ Corresponding author.

E-MAIL c.okane@gen.cam.ac.uk; FAX 44-1223-333992.

Article and publication are at http://www.genesdev.org/cgi/doi/10.1101/ $\operatorname{gad} .207801$.
}

minus of amphiphysin is capable of oligomerization (Wigge et al. 1997a; Ramjaun et al. 1999) and of tubulating lipids, either alone or cooperatively with dynamin (Takei et al. 1999). The central region harbors AP2- and clathrin-binding motifs (Dell Angelica et al. 1998; Owen et al. 1998; ter Haar et al. 2000), although in some amphiphysin 2 splice variants, these motifs are absent. Amphiphysins also possess a C-terminal SH3 domain whose major binding partners are the endocytic proteins dynamin and synaptojanin (David et al. 1996; McPherson et al. 1996; Ramjaun et al. 1997).

An endocytic function for amphiphysin is further suggested by the results of dominant-negative overexpression experiments. For example, expression of the central region of amphiphysin 1 blocks endocytosis (Slepnev et al. 1998, 2000). In addition, overexpression in lamprey synapses of the SH3 domain leads to the accumulation of coated pits and a reduction in neurotransmitter release in response to high-frequency stimulation (Shupliakov et al. 1997). Expression of the SH3 domain in cultured mammalian cells also impairs endocytosis, and this impairment is rescued by coexpression of dynamin (Wigge et al. 1997b). 
Alternative functions for amphiphysin have also been proposed. For instance, a splice form of amphiphysin 2 that possesses a nuclear localization signal inhibits malignant cell transformation by myc (Sakamuro et al. 1996). The two yeast amphiphysin homologs, Rvs161p and Rvs167p, have many proposed functions, including actin localization (Munn et al. 1995). Amphiphysin 2 splice variants that lack the clathrin-binding region are highly expressed in muscles and are likely to be localized on T-tubules, where their role is undetermined (Butler et al. 1997).

We have studied the function of amphiphysin in Drosophila by disrupting the only gene for this protein. Surprisingly, flies lacking amphiphysin are viable and have little or no detectable defect in synaptic vesicle endocytosis. However, they are flightless and have severe structural defects in the excitation-contraction coupling machinery of muscles. This indicates a novel role for amphiphysin in muscle function.

\section{Results}

Generation of null mutations in the Drosophila amphiphysin gene

Comparison of amphiphysin cDNA and EST sequences with genomic sequence allowed us to define the amphiphysin transcription unit (Fig. 1A). The gene contains 10 exons and occupies $\sim 17.5 \mathrm{~kb}$ of DNA. A homozygous viable $P$ insertion, $E P(2) 2175$, lies 47 bp upstream of the amphiphysin cDNA, LD19810 (Liao et al. 2000; Razzaq et al. 2000). This insertion was mobilized to generate a number of imprecise excisions; one of these, $a m p h^{26}$ (hereafter referred to as $a m p h^{m u t}$ ), had a deletion of the first exon including the beginning of the coding region, and part of the first intron of the amphiphysin gene (Fig. 1A). A precise excision that left the amphiphysin genomic region intact, $a m p h^{+1}$ (hereafter referred to as $a m p h^{+}$, was also recovered and used as a wild-type control in subsequent experiments. Western blots detected a number of related amphiphysin proteins in $a m p h^{+}$flies, perhaps generated by alternative transcripts, or by physiological or artifactual protein degradation. All of these were absent in $a m p h^{\text {mut }}$ homozygotes (Fig. 1B), and we therefore conclude that $a m p h^{m u t}$ is a null allele of the amphiphysin gene.

Unexpectedly, in light of the proposed central role for amphiphysin in endocytosis, $a m p h^{m u t}$ flies were viable and fertile both when homozygous, and when transheterozygous with a deficiency $D f(2 R) v g-C$, which deletes the amphiphysin genomic region. They also showed no

A

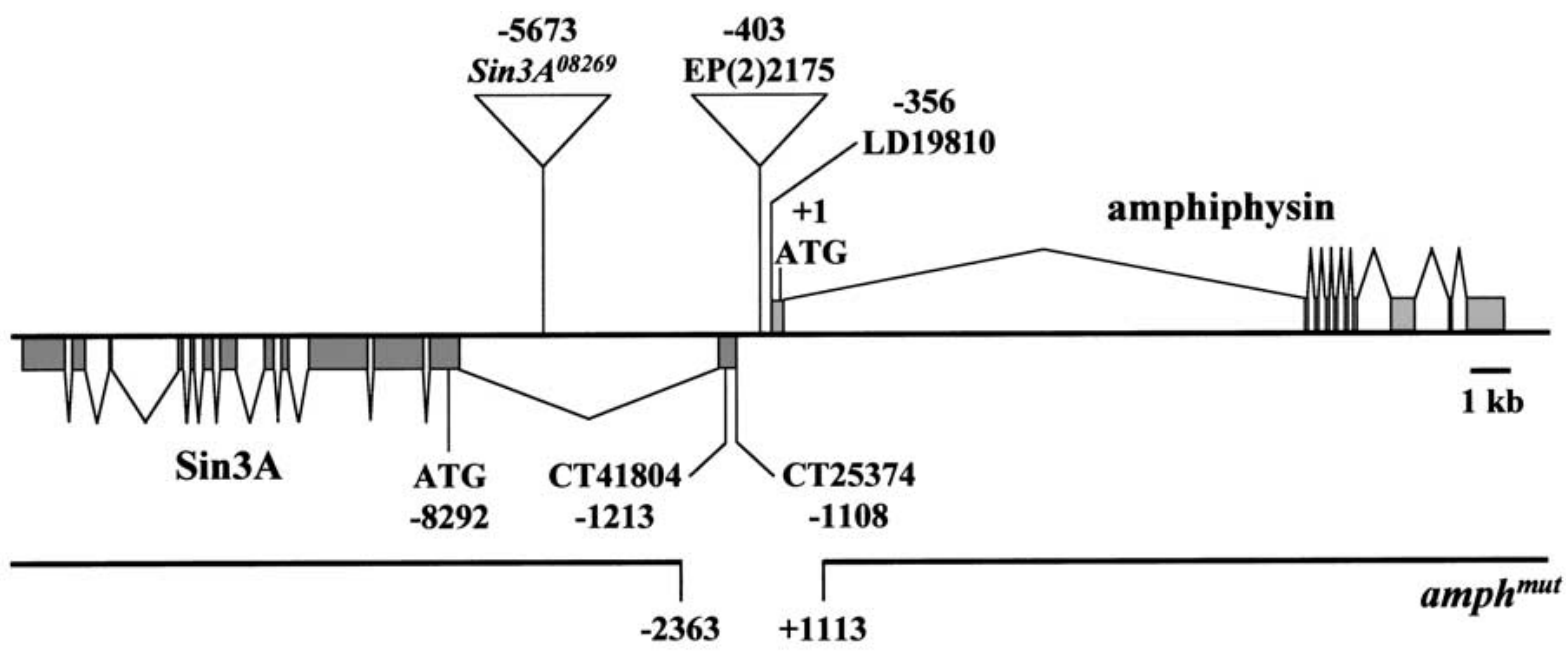

B

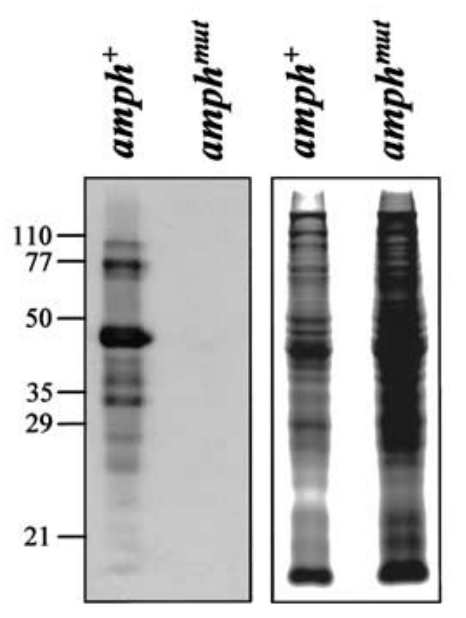

Figure 1. Generation of a Drosophila amphiphysin mutant. (A) Structure and mutagenesis of the amphiphysin gene. The intron/exon structure of the amph and $\operatorname{Sin} 3 A$ genes is shown, together with the positions of their start codons, two predicted transcription start sites of $\operatorname{Sin} 3 A$, and the insertion site of $P$-element $E P(2) 2175$. The breakpoints of the $a m p h^{m u t}$ excision are shown; it also contains an insertion of sequence TTTTATCAAAATTT at the deletion site. The approximate position of the $P$ insertion in $\operatorname{Sin} 3 A^{08269}$ is also shown; the locations of the lesions in the other $\operatorname{Sin} 3 A$ alleles are unknown at this level of resolution. All coordinates are given relative to the first nucleotide of the amphiphysin coding region (Razzaq et al. 2000). (B) A Western blot of $a m p h^{+}$and $a m p h^{m u t}$ homozygous flies probed with an antibody against Drosophila amphiphysin (left panel). Numbers indicate molecular masses in kilodaltons. A Coomassie-stained duplicate gel (right panel) allows comparison of protein loading. 
obvious external defects in eye, bristle, or wing pattern that might result from the interference with endocytic mechanisms involved in wingless, EGF receptor, TGF$\beta /$ decapentaplegic, or Notch signaling (Vieira et al. 1996; Seugnet et al. 1997; Entchev et al. 2000; Dubois et al. 2001). Adult mutants were, however, flightless and generally sluggish when homozygous, or when transheterozygous with $D f(2 R) v g-C$. EP(2)2175 homozygotes, $a m p h^{+}$homozygotes, and $a m p h^{+} / D f(2 R)_{v g-C}$ heterozygotes all showed no mutant phenotype.

In addition to a deletion of the $5^{\prime}$ end of the $a m p h$ gene, amph ${ }^{m u t}$ also had a deletion of part of the first exon of the adjacent gene $\operatorname{Sin} 3 A$, but left its coding region intact (Fig. 1A). We could detect no impaired function of Sin3A by amph ${ }^{m u t}$. First, loss of Sin3A is homozygous lethal (Pennetta and Pauli 1998), whereas amph ${ }^{\text {mut }}$ is homozygous viable. Second, crosses between $a m p h^{\text {mut }}$ and four different $\operatorname{Sin} 3 A$ mutant alleles showed complementation for the flightless and sluggish phenotypes.

The distribution of amphiphysin protein is not consistent with a role in synaptic vesicle endocytosis

Vertebrate amphiphysins 1 and 2 are soluble proteins that are associated in vivo with synaptic vesicles (Lichte et al. 1992; Wigge et al. 1997a). Double staining for amphiphysin and either a synaptic vesicle marker (cysteine string protein, CSP; see Mastrogiacomo et al. 1994; Estes et al. 1996) or a marker that is essentially postsynaptic using optical microscopy (Discs-large, DLG; Lahey et al. 1994) showed that amphiphysin was detectable only postsynaptically at the larval neuromuscular junction (NM); Fig. 2A-D). Amphiphysin was found only around type I boutons, where its distribution overlapped with that of DLG, a membrane-associated guanylate kinase (MAGUK) that is responsible for clustering ion channels and cell adhesion molecules (Dimitratos et al. 1999). No amphiphysin was detected around type II boutons (Fig. 2A), which lack DLG protein postsynaptically (Lahey et al. 1994; Woods et al. 1997). Although we cannot rule out low levels of presynaptic amphiphysin, or its presence on the presynaptic plasma membrane of type I boutons (indistinguishable from the postsynaptic compartment by optical microscopy), its absence from type II boutons and from the vesicle-containing cytosolic region of type I boutons suggests that it is unlikely to be required for synaptic vesicle recycling. No amphiphysin staining was found postsynaptically at amph ${ }^{\text {mut }}$ larval NMJs (Fig. 2E). However, postsynaptic structure, visualized by DLG staining, was intact in $a m p h^{\text {mut }}$ larvae, showing that amphiphysin was not required for the gross structural organization of the postsynaptic NMJ.

\section{Amphiphysin mutants have no major defects in synaptic transmission at the NMJ}

Mutations affecting endocytic proteins have pronounced effects on synaptic transmission in flies. For example, mutations in both lap (AP180) and stoned show reduced excitatory junction potential (EJP) amplitudes, increased variance in EJP size, and increased numbers of failures (Stimson et al. 1998; Zhang et al. 1998; Fergestad et al. 1999|. In contrast, EJP amplitude was unaffected in $a_{m p h}^{\text {mut }}$ larvae (Fig. 2F,G), and failures in synaptic transmission were never observed. High frequency stimulation results in a progressive rundown in EJPs in stoned and shibire mutants, owing to failure to replenish the vesicle pool by endocytosis (Fergestad et al. 1999; Li and Schwarz 1999; Delgado et al. 2000; also see Fig. 2H). In all lines tested, there is an apparent initial rapid decrease in the EJP amplitude during high frequency stimulation, caused by a depletion of the synaptic vesicle pool during the first few stimulations (Delgado et al. 2000), and by a failure of the muscle to return to its resting membrane potential during the interpulse period of 50 msec. However, shibire ${ }^{t s 1}$ (at the permissive temperature), $a m p h^{+}$, and $a m p h^{m u t}$ larvae showed only a continuing slow decrease in EJP amplitude, in contrast to the much faster and more pronounced decrease observed in shibire $e^{t s}$ mutants at their restrictive temperature (Fig. $2 \mathrm{H}$ ). Compared with $a m p h^{+}$and shibire ${ }^{t s}$ (at the permissive temperature), $a m p h^{\text {mut }}$ larvae had a larger initial drop in EJP amplitude, but the continued decline phase appeared similar in all these genotypes. Although we cannot rule out a mild defect in vesicle recycling, the subtle electrophysiological changes seen in $a m p h^{\text {mut }}$ larvae could also be explained by small changes in postsynaptic excitability (e.g., receptor or channel numbers or differences in desensitization). Nevertheless, because $a m p h^{\text {mut }}$ larvae clearly show a much milder phenotype than that of shibire $e^{t s}$ larvae at their restrictive temperature, amphiphysin cannot be an absolute requirement for synaptic vesicle recycling at the NMJ.

The amph mutants also showed a small increase in amplitude of miniature excitatory junction potentials (mEJPs; Fig. 2I,J), but no significant effect on mEJP frequency (Fig. 2K). Given the localization of amphiphysin at the postsynaptic NMJ of wild-type larvae, the increased mEJP amplitude in the mutant may reflect subtle changes in the postsynaptic physiology of the NMJ.

\section{Protein interactions of Drosophila amphiphysin} and vertebrate amphiphysin 2

In Drosophila, amphiphysin exhibits strong postsynaptic expression, whereas in mammalian tissue, it is highly enriched in the brain (Fig. 3A) and found presynaptically (Lichte et al. 1992; Wigge et al. 1997a). However, one or more splice forms of mammalian amphiphysin 2 that lack a consensus clathrin-binding motif are also highly expressed in skeletal muscle (Fig. 3A; Butler et al. 1997; Wechsler-Reya et al. 1997; see Materials and Methods) and are similar to the amphiphysin splice form (Amph 2-6) cloned from kidney (Wigge et al. 1997a).

Using pull-down assays, we tested the binding of glutathione-S-transferase (GST) fusions of the N- and C-terminal domains of Drosophila amphiphysin and rat amphiphysin 2-1 (Amph 2-1), as well as that of whole rat 

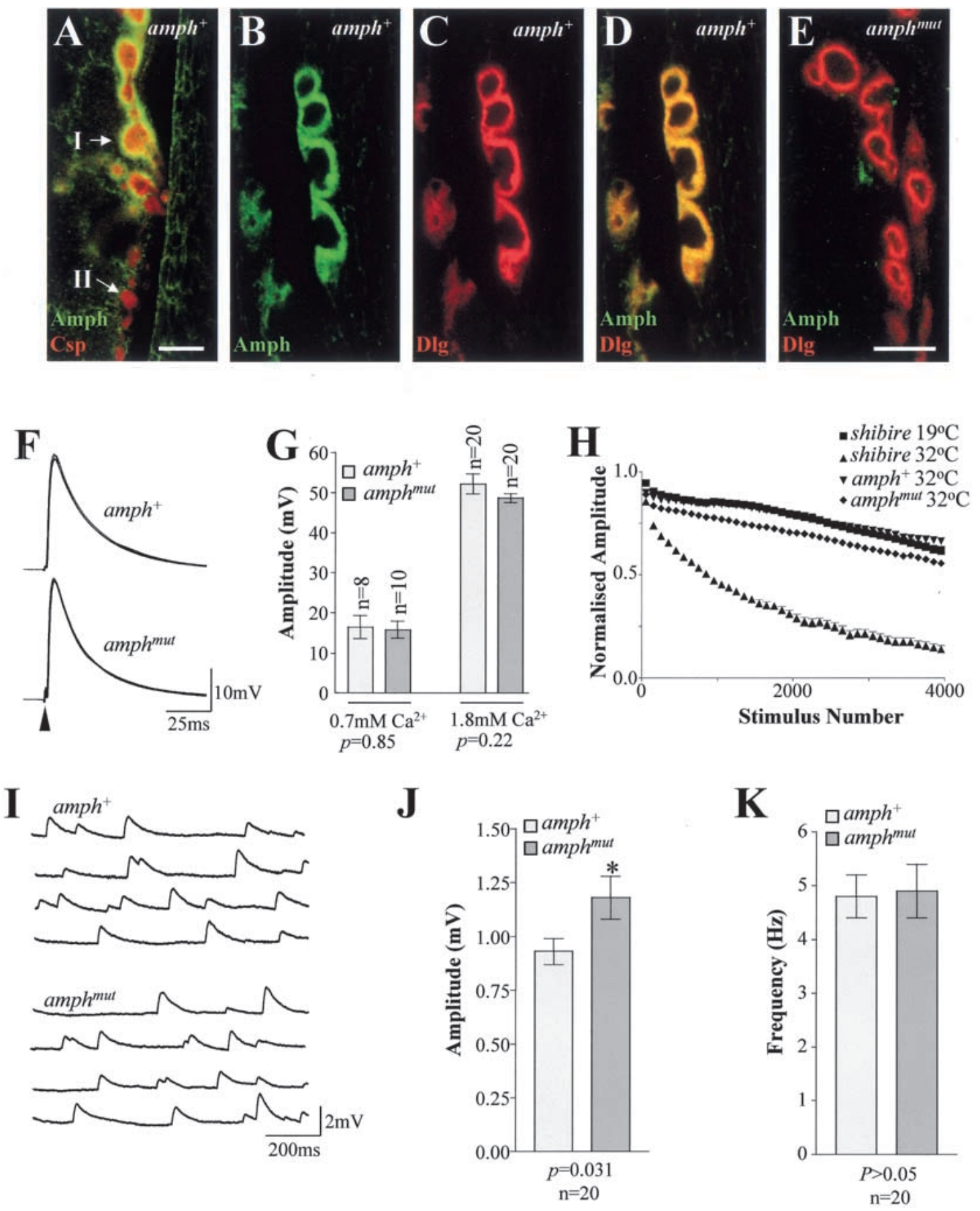

Figure 2. Amphiphysin is localized postsynaptically at the Drosophila larval NMJ and is not necessary for synaptic vesicle recycling. (A) Double labeling of a homozygous $a m p h^{+} \mathrm{NMJ}$ on larval body wall muscle 12 for cysteine string protein (CSP, presynaptic, red) and amphiphysin (Amph, green). Only the postsynaptic compartments of the larger type I boutons (I) have detectable amphiphysin staining; the smaller type II boutons (II) do not. Labeling of homozygous amph ${ }^{+}$type I boutons on larval body wall muscle 7 for amphiphysin $(B)$, the mainly postsynaptic marker DLG $(C)$, and both proteins $(D) .(E)$ Double labeling of homozygous amph ${ }^{\text {mut }}$ type I boutons on larval body wall muscle 7 for DLG (red) and amphiphysin (green). Bars, $A$ and $B-E, 5 \mu m$. (F) Five representative traces showing excitatory junction potentials (EJPs) evoked by $1 \mathrm{~Hz}$ stimulation, recorded from muscle 6 in third instar larvae from wild-type $\left(a m p h^{+1} / D f(2 R)_{V g-C}\right.$ labeled $\left.a m p h^{+}\right)$and mutant $\left(a m p h^{26} / D f(2 R)_{V g}-C\right.$; labeled $\left.a m p h^{m u t}\right)$ lines. Loss of amphiphysin has no effect on either the time course $(F)$ or the amplitude $(G)$ of the responses observed. $(H)$ High frequency stimulation $(20 \mathrm{~Hz})$ of the motoneurone led only to a slow rate of rundown in the evoked response recorded from $a m p h^{\text {mut }}$ homozygotes and $a m p h^{+}$homozygotes at $32^{\circ} \mathrm{C}$, and from shibire $e^{t s 1}$ larvae at the permissive temperature $\left(19^{\circ} \mathrm{C}\right)$. In contrast, there was a very rapid and extensive rundown in the EJP amplitude recorded from shibire ${ }^{t s 1}$ larvae at the restrictive temperature $\left(32^{\circ} \mathrm{C}\right)$. $(I)$ Four representative traces of recordings of spontaneous neurotransmitter release (mEJPs) are shown from wild-type and mutant animals. There was a small (but significant; $P=0.03$ ) increase in amplitude of the $\mathrm{mEJPs}$ recorded from mutant muscles $(J)$, but the frequency of these events was not altered $(K)$. 

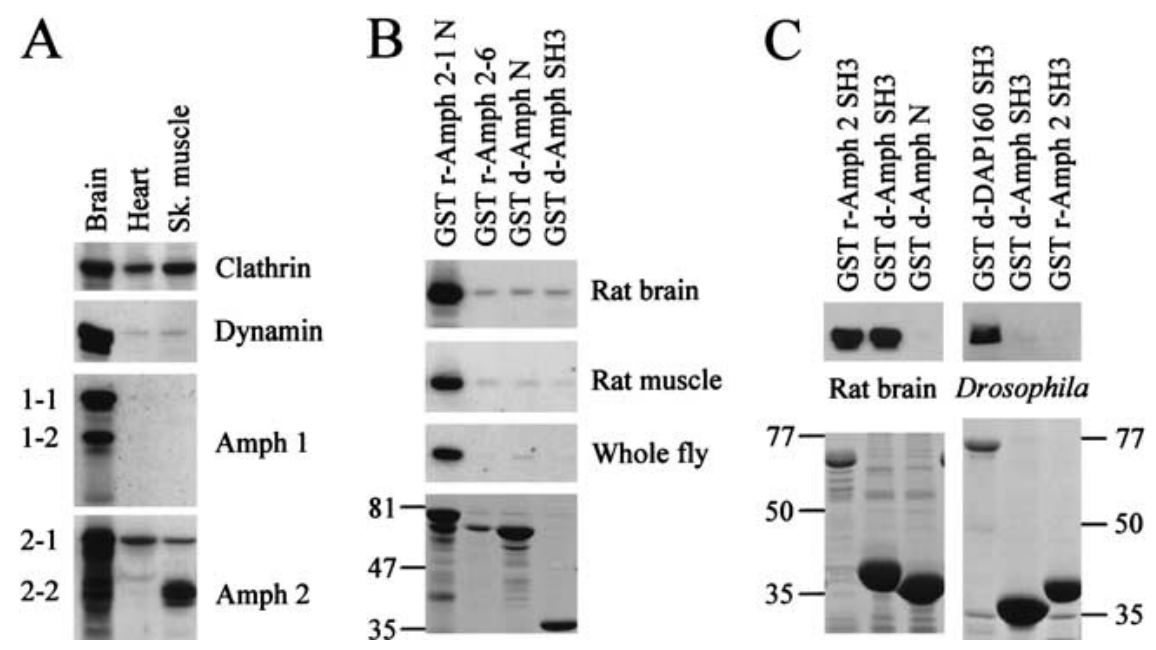

T-tubule defects in amphiphysin mutants

muscle extracts, and from whole Drosophila extract. The N terminus of rat amphiphysin 2 (GST r-Amph 2-1 N) interacts with clathrin in rat brain, rat skeletal muscle, and Drosophila extracts. Rat amphiphysin 2-6 (GST r-Amph 2-6) and the N terminus of Drosophila amphiphysin (GST d-Amph N), both of which lack consensus sequences for clathrin binding, were also probed. The residual band detected in rat brain and muscle tissues is nonspecific as it is also seen with the Drosophila amphiphysin SH3 domain (GST d-Amph SH3; negative control). Blots (top three panels) were probed with the X22 monoclonal antibody, which detects both the muscle and brain forms of clathrin (Liu et al. 2001). A Coomassie-stained duplicate gel (bottom panel) shows each GST fusion protein after binding to whole fly extract; identical aliquots of fusion proteins were used for binding to rat extracts. The major band in each lane is the GST fusion protein, and the other bands are a mixture of its degradation products and of its binding partners. Numbers indicate molecular masses in kilodaltons. (C) Dynamin binding to SH3 domains of amphiphysins. Rat brain dynamin (detected with a dynamin I monoclonal antibody, top left panel) bound to the SH3 domains from both rat amphiphysin 2 (GST r-Amph2) and Drosophila amphiphysin (GST d-Amph SH3). GST d-Amph N was used as a negative control for binding. In Drosophila extract, the interaction of the SH3 domains with dynamin (detected with an antibody against Drosophila dynamin, top right panel) was barely visible in comparison with the DAP160 SH3a,b,c,d domain (GST d-DAP160 SH3, positive control) which has previously been shown to interact strongly with Drosophila dynamin (Roos and Kelly 1998). Upon higher exposures, weak dynamin binding to both GST d-Amph and GST r-Amph 2 SH3 domains was detectable. Coomassie-stained duplicate gels (bottom panels) show each GST fusion protein after binding to extracts. The major band in each lane is the GST fusion protein, and the other bands are a mixture of its degradation products and of its binding partners. Numbers indicate molecular masses in kilodaltons.

Amph 2-6, to rat brain, rat muscle, and whole Drosophila protein extracts (Fig. 3B,C). The $\mathrm{N}$ terminus of the brain-enriched form, Amph 2-1, has a clathrin-binding consensus sequence and binds clathrin (Fig. 3B). Amph 2-6 and Drosophila amphiphysin lack this sequence, failed to bind clathrin (Fig. 3B), and are therefore unlikely to participate in clathrin-mediated endocytosis. The SH3 domains of rat amphiphysin 2 and Drosophila amphiphysin bound to rat brain dynamin, but not to Drosophila dynamin (Fig. 3C). The latter is probably a consequence of the lack of conservation of the consensus amphiphysin SH3-binding motif (PxRPxR; see Owen et al. 1998) in Drosophila dynamin. In contrast, the SH3 domains of DAP160 (Roos and Kelly 1998), the Drosophila intersectin homolog, bound strongly to Drosophila dynamin (Fig. 3C). The failure of Drosophila amphiphysin to interact significantly with Drosophila dynamin also argues against an endocytic role in Drosophila.

\section{Amphiphysin is localized on muscle T-tubules}

Amphiphysin expression was not limited to the neuromuscular junction and was also found throughout larval body wall and adult thoracic muscles, localized on a re- ticular network (Fig. 4A,C). A similar network in larval body wall muscles has previously been shown using antibodies against DLG (Thomas et al. 2000).

Amphiphysin distribution was analyzed in most detail in indirect flight muscles (IFMs; Fig. 4C), highly specialized muscles that can contract at up to $300 \mathrm{~Hz}$ (Crossley 1978). In IFMs, amphiphysin is found on an extensive network of transverse and longitudinal projections that ramify around and between myofibrils. These transverse projections overlie sarcomeres periodically at positions midway between the $\mathrm{M}$ and $\mathrm{Z}$ lines (see Fig. 4D for positions of the latter), at which myosin and actin filaments, respectively, are anchored. The positions of transverse projections coincide with the locations of junctions formed by close apposition of the T-system to the junctional sarcoplasmic reticulum (jSR). These $\mathrm{T}$-jSR junctions play a vital role in excitation-contraction coupling, in which depolarization of the sarcolemma activates a voltage sensor between the T-tubule and the underlying ryanodine receptors (RyRs) on the jSR surface, thus leading to calcium release from the jSR and to muscle contraction.

Ultrastructural studies of IFMs of the Dipteran Phormia regina have established that they possess mainly dyadic T-jSR junctions (Smith 1961). Consistent with 

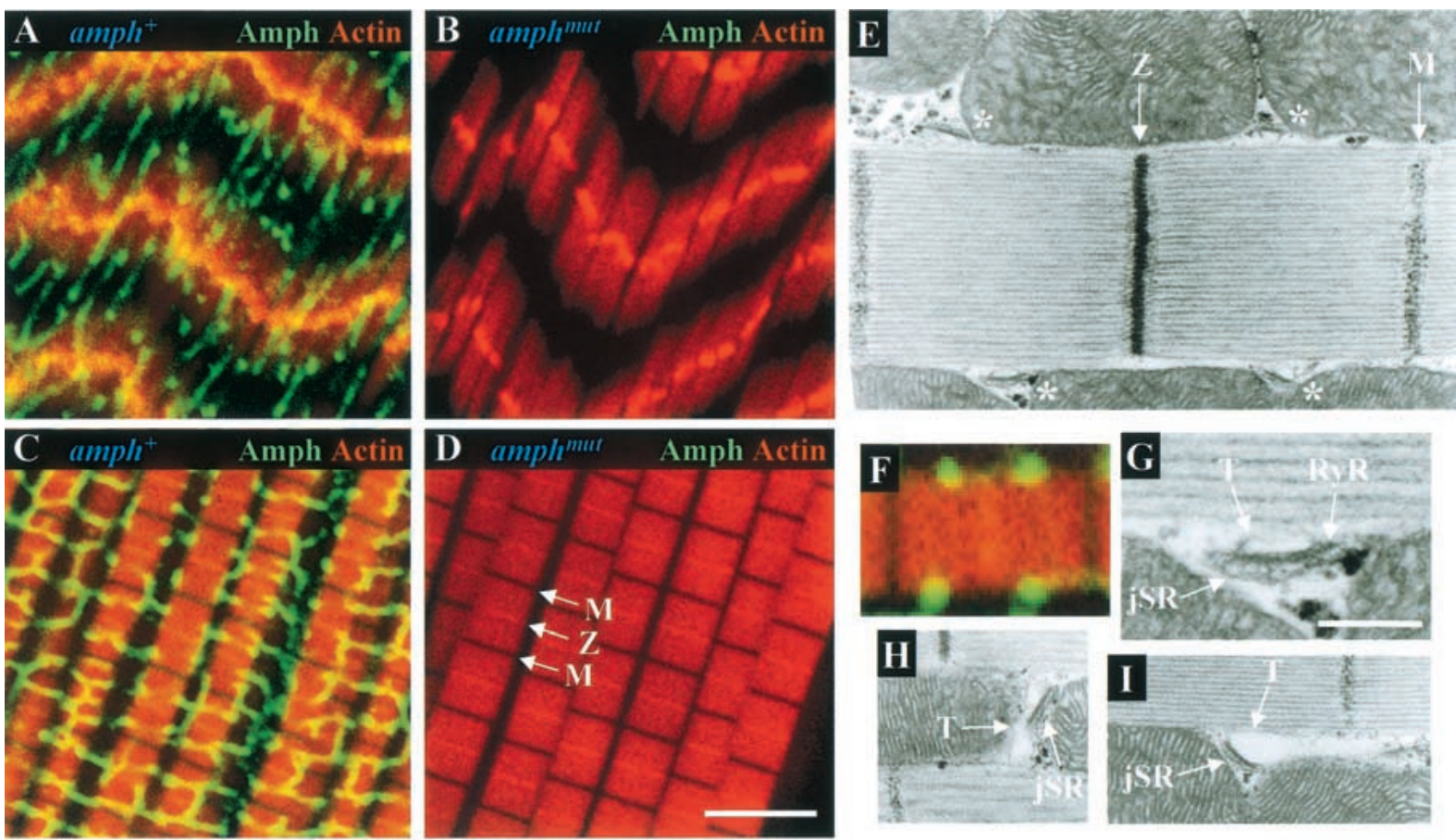

Figure 4. Amphiphysin is found on muscle T-tubules. Confocal sections of amphiphysin (Amph, green) and actin (red) double labeling in larval body wall muscles $(A, B)$ and adult IFMs $(C, D)$, from $a m p h^{+}(A, C)$ and $a m p h^{m u t}(B, D)$ homozygotes. In panel $D$, the locations of the $\mathrm{M}$ and $\mathrm{Z}$ lines are indicated. $(E, G-K)$ Electron micrographs of $a m p h^{+}$IFM longitudinal sections. (E) Longitudinal section through the center of a myofibril with dyads (asterisks) associated along each side of the myofibril at a region midway between the $\mathrm{M}$ and $\mathrm{Z}$ lines. (F) Amphiphysin (green) and actin (red) double labeling of a sarcomere similar to that of panel E. (G) Higher magnification of a dyad from panel $E$ showing the electron-lucent T-tubule and electron-dense jSR compartments, and

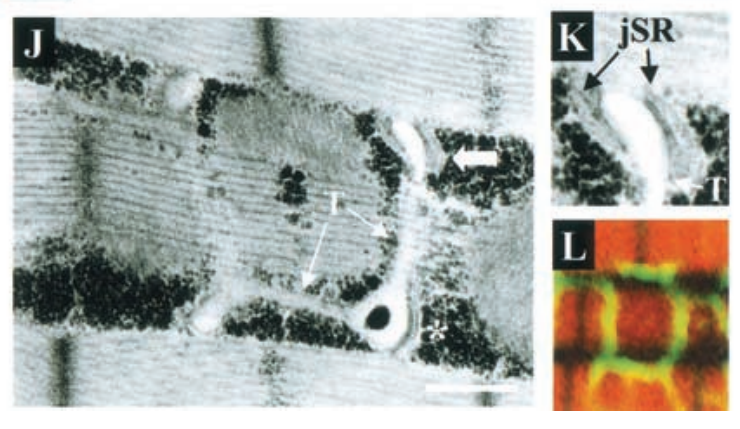
the RyR-containing density on the face of the jSR cisterna. Longitudinal sections through the peripheral surface of a myofibril showing the T-tubular compartments of dyads extending as tranverse $(H)$ or longitudinal $(I)$ projections away from the adjoining jSR. $(J)$ Longitudinal section grazing along the peripheral surface of a myofibril showing both transverse and longitudinal T-tubular projections extending from a dyad (asterisk) and a triad (broad arrow). (K) Higher magnification of the triad in panel $G$ showing the translucent T-tubule compartment flanked on either side by two jSR compartments. ( $L$ ) Amphiphysin (green) and actin (red) double labeling of a section along the top of a sarcomere, similar to that of panel $J$. Bar in $D$ (for panels $A-D$ ), $5 \mu \mathrm{m}$; bar in $G$ (for panels $G$ and $K$ ), $250 \mathrm{~nm}$; bar in $J$ (for panels $E, H-J), 500 \mathrm{~nm}$. All IFMs shown are dorsolongitudinal IFMs.

the observations of Shafiq (1964), we found that Drosophila IFMs also have dyadic junctions; these were generally localized alongside the sarcomere, midway between the $\mathrm{M}$ and $\mathrm{Z}$ lines (Fig. 4E). As in Phormia, the jSR component of the dyad is electron-dense, and the T-tubule electron-lucent (Fig. 4G; Block et al. 1988). In longitudinal sections along the peripheral surface of a myofibril, the lumina of the T-system were frequently seen to extend from dyads as transverse and longitudinal tubular processes that coursed between individual myofibrils and mitochondria (Fig. 4H,I). Classic triadic T-SR junctions consisting of two jSR cisternae flanking a single T-tubule were also seen occasionally (Fig. 4J,K). Again in agreement with previous ultrastructural observations in Phormia (Smith 1961; Smith and Sacktor
1970), the only compartments seen to extend into longitudinal and transverse projections belonged to the T-system (Fig. 4J). In contrast, sarcoplasmic reticulum (SR) was only found as jSR at dyadic junctions. A network of free SR, which should be visible as an extensive, fenestrated tubular network extending longitudinally along myofibrils, was either very sparse or absent from these muscles, a finding again consistent with previous observations (Smith 1961; Shafiq 1964; Smith and Sacktor 1970; Crossley 1978). We therefore conclude that the reticular amphiphysin staining in IFMs seen using immunofluoresence is the extensive T-system observed at the ultrastructural level. This localization is consistent with the reported presence of vertebrate amphiphysin 2 on the surface of skeletal muscle T-tubules (Butler et al. 1997). 
Excitation-contraction coupling machinery of amph mutants is severely disorganized

The flightless phenotype of amph mutants, and localization of amphiphysin at T-tubules, suggested a defect in muscle structure or function. Muscles of $a m p h^{m u t}$ homozygotes had no detectable amphiphysin (Fig. 4B,D). Despite this, mutant IFM structure was similar to that of wild type, although larval body wall muscles did display slightly looser packing of myofibrils.

In light of the similarity of the DLG staining of larval body wall muscles (Thomas et al. 2000) to that of amphiphysin (Fig. 4A), we compared the localization of both proteins in these muscles and in IFMs. There was substantial, but incomplete, overlap of the two proteins within the T-system (Fig. 5A-C,E-G), suggesting that DLG is also localized on T-tubules. Double labeling with antibodies to RyR and DLG (Fig. 5K) showed that the DLG-containing T-tubular network ran between, but did not colocalize with, RyR-containing jSR compartments that appeared as regular puncta alongside myofibrils, approximately midway between the $\mathrm{M}$ and $\mathrm{Z}$ lines (Fig. $5 \mathrm{I}, \mathrm{K})$.

In $a m p h^{\text {mut }}$ muscles, DLG staining showed that loss of amphiphysin resulted in severe disorganization and reduction of the T-system (Fig. 5D,H,L). In amph ${ }^{\text {mut }}$ IFMs, many transverse elements of the T-system were lost, and the remainder were predominantly longitudinal, and sometimes broader (Fig. 5H). Dyad junctions (visualized with antibody against RyR) were still apparent, but distributed irregularly, and occupied only $42 \%$ of the cell volume fraction they occupied in wild-type IFMs. They were often larger than in wild type, sometimes extending over half the length of a sarcomere (Fig. 5J,L). Only a sparse T-system was seen between expanded and mislocalized jSR compartments (Fig. 5L).

Electron microscopy of amph ${ }^{\text {mut }}$ IFMs broadly supported the conclusions drawn from confocal analysis. Thin sections of IFMs confirmed that the gross structure of mutant muscles was equivalent to wild type. Although dyads were still observed, they were no longer regularly distributed along the length of the sarcomere (Fig. 5M). The increased size of dyads seen using RyR staining (Fig. 5J,L) was corroborated by the elongated $\mathrm{T}$-jSR dyads often seen in thin sections (Fig. 5N). In agreement with the confocal observations, mutant T-tubules often had larger diameters (cf. Fig. 4H,I,J with Fig. $5 \mathrm{O}, \mathrm{P})$. The reduction and mislocalization of the $\mathrm{T} / \mathrm{SR}$ components suggests that $a m p h^{\text {mut }}$ flightlessness may be a consequence of a defect in excitation-contraction coupling.

Several lines of evidence indicate that the T-tubule defect is caused by loss of amphiphysin. First, the phenotype of transheterozygotes of $a m p h^{\text {mut }}$ over the deficiency $D f(2 R)_{V} g-C$, assessed by actin and RyR staining of IFMs, was identical to that of amph ${ }^{\text {mut }}$ homozygotes (data not shown). Second, RyR distribution in amph ${ }^{m u t} /$ $\operatorname{Sin} 3 A^{-}$IFMs was indistinguishable from wild type for all four $\operatorname{Sin} 3 A$ alleles tested (data not shown), showing that the phenotypes observed in muscles were not caused by impairment of Sin3A function. Third, we achieved substantial rescue of the amph ${ }^{\text {mut }}$ T-tubule phenotype by driving expression of the amphiphysin cDNA, LD19810, under control of a heat-shock-inducible GAL4 gene. Here we refer to $a m p h^{m u t}$ individuals that can express this cDNA as amph $h^{\text {rescue }}$ individuals (for details of genotypes and heat shock induction, see Materials and Methods). In contrast to $a m p h^{\text {mut }}$ flies, which were flightless and possessed a disrupted T-SR system (Fig. 6D,F), almost all amphescue individuals could fly, and they exhibited varying degrees of recovery of the T-system (Fig. $6 \mathrm{~A}-\mathrm{C}, \mathrm{E})$. All showed amphiphysin staining in a reticular pattern around individual myofibrils, which colocalized mostly with that of DLG. Although some flies had almost complete rescue of the T-SR defects (Fig. 6), many individuals had only partial rescue, in which the degree of amphiphysin branching and its ordered spacing midway between the $\mathrm{M}$ and $\mathrm{Z}$ lines was highly variable (data not shown). Interestingly, even when rescue of $\mathrm{T}$-system morphology was only partial, most individuals could still fly, suggesting that the precisely ordered spacing of the T-system is not absolutely essential for flight.

\section{Tubulation abilities of Drosophila amphiphysin} and rat amphiphysin 2

As the $\mathrm{N}$ terminus of rat amphiphysin 1 has the ability to tubulate lipids in vitro (Takei et al. 1999), we tested whether rat Amph 2-6 and Drosophila amphiphysin also had this ability. Both full-length Amph 2-6 and the Drosophila amphiphysin $\mathrm{N}$-terminal domain readily promoted the formation of tubular projections from the surface of liposomes within the time necessary for their preparation for electron microscopy (Fig. 7). The amphiphysin protein forms the scaffold for these lipid projections. The diameters of the T-tubules in IFM electron micrographs (Fig. 4H-J) are, on average, wider than the projections generated in vitro from Folch lipids (Fig. $7 \mathrm{~B}, \mathrm{C})$. This difference may be a consequence of the diameter in vivo being governed by different lipid contents, as well as by additional proteins present in T-tubule projections, such as DLG. In conclusion, both rat Amph 2-6 and Drosophila amphiphysin have the potential to initiate tubule extensions of lipid membranes similar to those seen within the reticular T-tubule network of muscles.

\section{Discussion}

Drosophila amphiphysin has no essential role in synaptic vesicle endocytosis

Taken together, our results suggest that amphiphysin has no essential role in clathrin-mediated endocytosis in Drosophila. First, Drosophila amphiphysin lacks motifs for binding to clathrin, fails to bind either vertebrate or Drosophila clathrin, and does not interact strongly with Drosophila dynamin. Second, at the larval NMJ, the protein is not detected on or around synaptic vesicles, and amph mutants have little if any discernible defect in synaptic transmission even during prolonged stimula- 

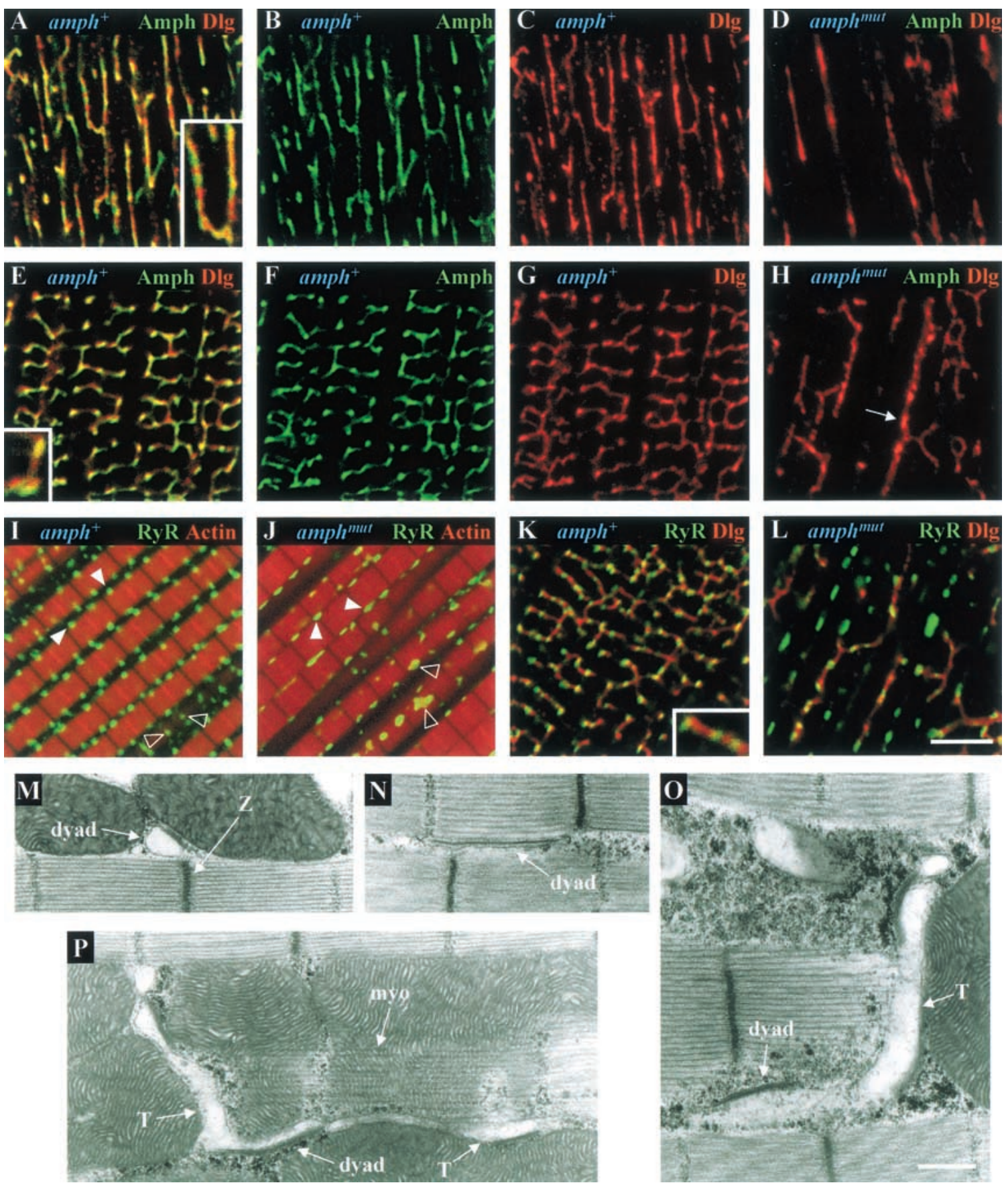

Figure 5. Organization of the excitation-contraction coupling machinery of muscles is disrupted in amphiphysin mutants. Confocal sections showing amphiphysin (Amph, green) and Discs-large (DLG, red) labeling in larval body wall muscles $(A-D)$ and adult IFMs $(E-H)$ from $a m p h^{+}(A-C, E-G)$ and $a m p h^{m u t}(D, H)$ homozygotes. Arrow in panel $H$ indicates a longitudinal mutant T-tubule with increased diameter. Double staining of homozygous $a m p h^{+}(I)$ and $a m p h^{m u t}(J)$ IFMs for Ryanodine receptor (RyR, green) and actin (red). Here, closed arrowheads indicate dyads located in longitudinal sections through the center of a myofibril, and open arrowheads indicate dyads situated in longitudinal sections through the peripheral surface of myofibrils. Double staining of homozygous amph ${ }^{+}$ $(K)$ and $a m p h^{m u t}(L)$ IFMs for RyR (green) and DLG (red). Bar in $L$ (panels $A-L$ ), $5 \mu \mathrm{m}$. Insets in panels $A, E$, and $K$ are magnified further by a factor of 1.8. $(M-P)$ Electron micrographs of longitudinal sections through homozygous amph ${ }^{\text {mut }}$ IFMs. Longitudinal sections through the center of a myofibril showing $(M)$ a dyad mislocalized to the $\mathrm{Z}$ band, and $(N)$ an elongated dyad extending half the length of the sarcomere, identified by the RyR-containing density on the surface of the jSR. Longitudinal sections through the peripheral surface of a myofibril showing elongated dyads extending into $(O)$ a transverse or $(P)$ transverse and longitudinal T-tubule projections that have greater than normal diameters. The myofibril (myo) is highlighted in panel $P$. Bar in $O$ (for panels $M-P$ ), $500 \mathrm{~nm}$. All IFMs shown are dorsolongitudinal IFMs. 

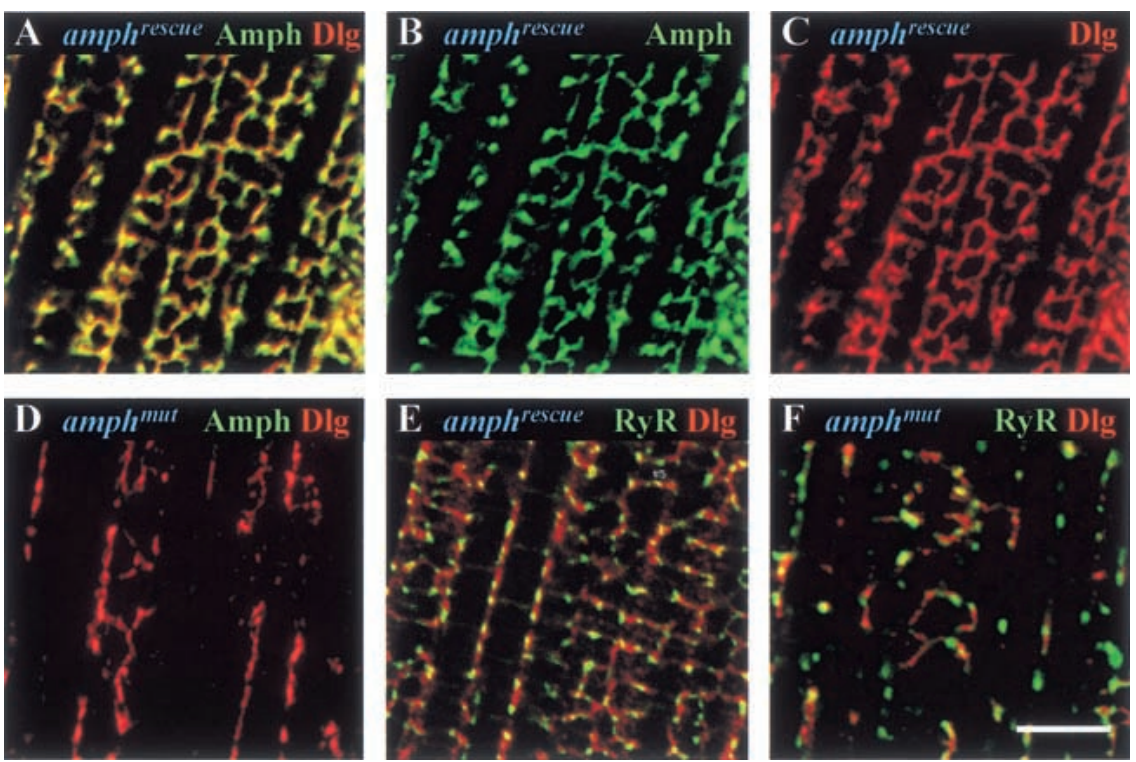

Figure 6. Expression of an amphiphysin cDNA rescues disruption of the T-SR system in amphiphysin mutants. Confocal sections of amphiphysin (Amph, green) and Discs-large (DLG, red) double-labeling $(A-D)$, and of Ryanodine-receptor (RyR, green) and Discs-large (DLG, red) doublelabeling $(E, F)$, in IFMs of $a m p h^{\text {mut }}$ flies that express cDNA LD19810 under control of an hs-GAL4 construct $\left(a m p h^{\text {rescue }}\right.$, $A-C, E)$ and $a m p h^{m u t}$ control flies $(D, F)$ that do not express this cDNA (for details of genotypes, see Materials and Methods). Bar, $5 \mu \mathrm{m}$. All individuals were raised at $25^{\circ} \mathrm{C}$ and subjected to a daily heat shock of $37^{\circ} \mathrm{C}$ for $30 \mathrm{~min}$ throughout development. tion, suggesting that synaptic vesicle recycling is largely if not entirely intact. Third, amph mutants were viable and fertile, suggesting no gross impairment of endocytosis in nonneuronal cells. The lack of endocytic mutant phenotypes is unlikely to be owing to gene redundancy as only one amphiphysin gene is known in the Drosophila genome.

In contrast to Drosophila, vertebrate amphiphysin is localized on or around synaptic vesicles and binds to multiple endocytic proteins, and dominant-negative forms produce severe endocytic phenotypes. These results provide evidence that vertebrate amphiphysin plays an important role in endocytosis, cooperating with dynamin in the vesicle scission step. Our results do not contradict an endocytic function for vertebrate amphiphysin, but rather suggest that this function is less highly conserved than that of dynamin. In Drosophila nerve terminals, alternative proteins like Dap160, which binds Drosophila dynamin and other endocytic proteins, could fulfill functions such as dynamin recruitment that are proposed to be mediated by amphiphysin in vertebrates.
Mutations affecting the yeast amphiphysin homologs Rvs161p and Rvs167p cause defects in both endocytosis and the actin cytoskeleton (Munn et al. 1995). However, interpretation of the role of these gene products in endocytosis is complicated first by their effects on the actin cytoskeleton, as actin mutations also have endocytic defects (Munn et al. 1995), and second by the fact that clathrin and dynamin have not been reported as binding partners of Rvs161p or Rvs167p (Bon et al. 2000). Alternatively, lipid tubulation properties of the N-terminal domain of amphiphysin might represent a more ancient function of amphiphysin than its interactions with clathrin and dynamin, as this domain is conserved in yeast, Caenorhabditis, Drosophila, and mammalian amphiphysins. This function may have been adapted to both endocytic and nonendocytic roles. Indeed, amphiphysin may also have nonendocytic roles in vertebrates; the properties of Drosophila amphiphysin are similar to those of a muscle-specific splice variant of vertebrate amphiphysin 2, which also lacks a clathrin-binding site and is probably localized on T-tubules (Butler et al. 1997).
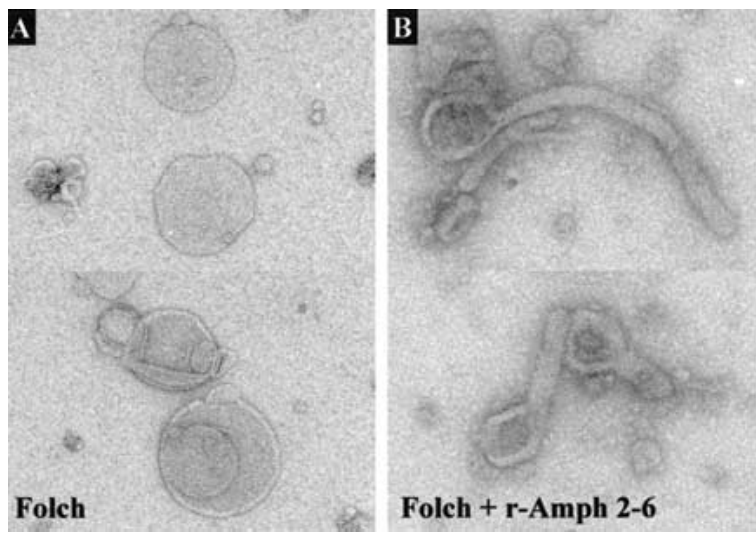

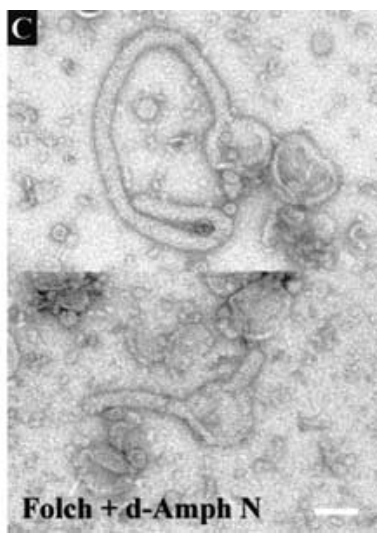

Figure 7. Tubulation of liposomes by ratAmph 2-6 and a Drosophila amphiphysin $\mathrm{N}$-terminal domain. Folch liposomes show tubule protrusions in the presence of amphiphysin proteins. Undecorated Folch liposomes $(A)$ were partially tubulated by addition of either $(B)$ full-length vertebrate Amph 2-6 or $(C)$ an N-terminal Drosophila amphiphysin domain (d-Amph N). Tubule protrusions formed by full-length vertebrate Amph 2-6 had wider apparent diameters than those of $\mathrm{d}$-Amph $\mathrm{N}$ owing to the use of full-length Amph 2-6 protein, in contrast to just the $\mathrm{N}$-terminal domain of Drosophila amphiphysin. Bar, $100 \mathrm{~nm}$. 


\section{Role of amphiphysin in T-tubule organization}

Comparison of the reticular localization of amphiphysin seen using confocal microscopy, with electron microscopy of the T-SR system, suggests that Drosophila amphiphysin is localized on muscle T-tubules. As vertebrate amphiphysin 2 is also found on muscle T-tubules, this suggests a conserved function for amphiphysin on these invaginations of the plasma membrane. Indeed, in flies that lack amphiphysin, T-SR junctions and T-tubule projections were greatly reduced in number and generally mislocalized, and remaining T-SR junctions were often larger than normal. Therefore, amphiphysin is essential for organization and normal morphology of the T-system.

We can envisage a number of ways in which amphiphysin might achieve this. First, the N-terminal portion of amphiphysin can tubulate lipids, and such an activity might contribute to T-tubule formation or stabilization. Although some T-tubules can still form even in the absence of amphiphysin, the reduction in transverse elements of the T-system means that amphiphysin might play a role in tubule branching, either alone or in cooperation with other proteins. Second, amphiphysin might have a cytoskeletal role in anchoring transverse $\mathrm{T}$-tubules close to the myofibril, approximately midway between the Z-line and the M-line. The yeast amphiphysin homologs interact with a number of components of the actin cytoskeleton (Bon et al. 2000), and similar interactions of amphiphysin could account for both the regular positioning of the transverse elements of the T-system in wild-type flies and the slightly looser arrangement of myofibrils in larval body wall muscles in the mutant. Third, the altered organization of T-tubules and T-SR junctions suggests that amphiphysin plays a role in organizing the protein components of T-tubules. Vertebrate T-tubules contain several cell adhesion and associated cytoskeletal proteins (Tuvia et al. 1999) and have subdomains that are defined by the presence of different membrane proteins (Scriven et al. 2000). Surprisingly, we also detected DLG protein on T-tubules (Fig. 5) in domains that partially overlap with those of amphiphysin expression. DLG and its vertebrate homologs, such as PSD-95, play an important role in localizing channels and cell adhesion proteins at synapses (Dimitratos et al. 1999|, and it could play an analogous role in T-tubules. These models of amphiphysin function are not mutually exclusive. Testing them will involve addressing questions such as the interactions that localize T-tubules to the middle of the $\mathrm{M}-\mathrm{Z}$ interval, the binding partners of the SH3 domain of Drosophila amphiphysin if they do not include dynamin, and the contribution of other proteins to morphology of the T-system. One protein of potential relevance might have been caveolin, as the initial stages of vertebrate T-tubule formation may be analogous to caveola formation, and caveolin 3 is found on vertebrate T-tubules (Carozzi et al. 2000). However, we can detect no caveolin homolog in the Drosophila genome.

Implications for muscle function and pathology

A predicted consequence of disrupted T-system would be altered spatial and temporal dynamics of calcium flux in the cytoplasm. Elevations in calcium concentration following muscle depolarization are first seen at discrete regions before the calcium gradients dissipate (Monck et al. 1994), and alterations in calcium dynamics might reduce the extent, speed, and synchronization of muscle contraction. Although this would not entirely block muscle contraction, it would probably interfere with the rapid coordinated cycles of contraction and relaxation of IFMs.

Given the localization of vertebrate amphiphysin 2 on T-tubules (Butler et al. 1997), mutations in human amphiphysin 2 might be implicated in myopathies that are associated with defects in excitation-contraction coupling. Experimentally induced congestive heart failure can lead to a disorganization and reduction in number of T-tubules in cardiac myocytes (He et al. 2001). Furthermore, the human conditions of malignant hyperthermia and central core disease have been linked to mutations affecting other components of excitation-contraction coupling, RyR or the L-type calcium channel (MacLennan 2000). It is possible that myopathies that map to other loci might involve amphiphysin. The phenotypes of mice deficient in amphiphysin 2 should help clarify this question.

In conclusion, our results shed new light on the role of amphiphysin within a broader physiological and phylogenetic context. The use of Drosophila as a model organism offers not only the advantage of powerful genetics and functional analysis, but allows novel nonendocytic roles of amphiphysin to be studied in a situation where they are not masked by its endocytic functions.

\section{Materials and methods}

\section{Genetics}

Excisions of EP(2)2175 were generated (O'Kane 1998) by crossing to a stock carrying the transposase insertion $\mathrm{P}\left\{r \mathrm{Y}^{+}, \Delta 2-3\right\} 99 B$ (Robertson et al. 1988). Progeny of individuals that had lost the $W^{+}$marker were used to make stocks that were screened for excisions by PCR and sequencing. The reverted excision site of $a \mathrm{ph}^{+1}$ homozygotes was verified using primers 5'-GCGCGC TGCGTCTGG-3' (-1232 to -1218$)$ and 5'-CCAAACAATATC GGCCCCACAC-3' (-182 to -203). The $a m p h^{26}$ excision in homozygous flies was characterized using primers $5^{\prime}$-CACCAAA GGGTACATTGAGCTGCC-3' (-2510 to -2486) and 5'-GCAT CCGCAAGATGCTGTGTG-3' (1470 to 1450). All primers are numbered relative to the first nucleotide of the amph coding sequence. For complementation tests, $a m p h^{26}$ homozygotes were crossed to $\operatorname{Sin} 3 A^{-} / C y O$ mutant stocks, and non-curly progeny were assessed for $a m p h^{26}$ mutant phenotypes. The four Sin3A mutant alleles used were $\operatorname{Sin} 3 A^{e 64}, \operatorname{Sin} 3 A^{\text {xe374 }}$ (Neufeld et al. 1998), Sin3 $A^{\text {k05415 }}$ (Pennetta and Pauli 1998), and $\operatorname{Sin} 3 A^{\text {k08269 }}$ (Liao et al. 2000), the latter two each harboring a $P$-insertion in the first intron of $\operatorname{Sin} 3 A$. Transheterozygous $a m p h^{+}$and $a m p h^{m u t}$ larvae were generated by crossing $a m p h^{+1}$ and $a m p h^{26}$ homozygotes, respectively, to $D f(2 R) v g-C / C y O$, Ubi-mycGFP flies (flies carrying plasmid pUGH constructed by Jan Qiu [Brandeis University, Waltham, MA], mobilized onto CyO by Paolo d'Avino [University of Cambridge, UK]) and selecting the non-GFP-expressing larval progeny.

For rescue of mutant phenotypes, expression of cDNA LD19810 (Razzaq et al. 2000), which had been cloned into the 
GAL4-dependent expression vector pUAST (Brand and Perrimon 1993) and inserted on chromosome 3, was driven by a heat-shock-inducible GAL4 insertion, hs-GAL4 (a kind gift of T.L. Schwarz, Harvard University, Boston, MA). Flies heterozygous for $a m p h^{m u t}$ and carrying either LD19810 or hs-GAL4 over a third chromosome balancer were mated to each other, to generate homozygous amph ${ }^{\text {mut }}$ progeny that carried either both LD19810 and hs-GAL4 (amph ${ }^{\text {rescue }}$ individuals, which could express amphiphysin), or only one of these constructs (effectively $\left.a m p h^{m u t}\right)$. The latter were used as nonexpressing controls in the rescue experiments. All progeny were raised at $25^{\circ} \mathrm{C}$ throughout development and given daily heat shocks for $30 \mathrm{~min}$ at $37^{\circ} \mathrm{C}$. Rescue and control flies were then assessed for flight ability (by observing whether they flew away when walking in an open space) and T-system integrity.

\section{Confocal markers and antibodies}

A rabbit antibody, Ra29, raised against the Drosophila amphiphysin SH3 domain (residues 525-602), was used for all experiments, except those in Figure 5A-D, at 1:500 dilution. Rabbit anti-Drosophila amphiphysin antibody 9906 (raised against residues 523-602 of the Drosophila amphiphysin SH3 domain and affinity-purified) was used at 1:250 for Figure 5A-D, and gave the same results as Ra29 in all immunomicroscopy. Monoclonal mouse anti-CSP (Reichmuth et al. 1995) was used at 1:250, polyclonal guinea pig anti-DLG (Woods et al. 1997) at 1:500, anti-RyR (Seok et al. 1992) at 1:20, and Texas-Red phalloidin (Molecular Probes) at 1:150 dilution.

\section{Immunocytochemistry}

Third instar larval dissections (Atwood et al. 1993) and thoracic dissections of IFMs (Peckham et al. 1990) were performed as described. Tissues were dissected directly in fixative $(4 \%$ formaldehyde in PBS: $10 \mathrm{mM}$ phosphate buffer, $2.7 \mathrm{mM} \mathrm{KCl}, 137$ $\mathrm{mM} \mathrm{NaCl}$ at $\mathrm{pH} 7.4$ ) for $20 \mathrm{~min}$. All subsequent washes and incubations were performed in blocking buffer $10.3 \%$ Triton $\mathrm{X}-100,0.1 \%$ bovine serum albumin, $2 \%$ donkey serum in PBS). Samples were blocked in four changes of buffer for $30 \mathrm{~min}$ each, then incubated at $4^{\circ} \mathrm{C}$ overnight in primary antibody. Samples were washed, incubated in donkey secondary antibody (Jackson laboratories, 1:250) for $60 \mathrm{~min}$, washed, mounted in Vectashield (Vector Laboratories), and visualized using a Bio-Rad Radiance confocal microscope. To estimate the volume fraction of muscle cells occupied by RyR immunoreactivity, a quadratic lattice was overlaid on 10 randomly selected fields of view from 5 wild-type and 5 mutant IFMs, and the number of points landing on immunoreactive elements was divided by the total number of points on the IFM.

\section{Ultrastructural analysis}

Adult IFMs were prepared essentially as in O'Donnell and Bernstein (1988), with modifications taken from Forbes et al. (1977). Adults aged 3-5 d were dissected in buffer $(5$ mM HEPES, 128 $\mathrm{mM} \mathrm{NaCl}, 2 \mathrm{mM} \mathrm{KCl}, 4 \mathrm{mM} \mathrm{MgCl}, 36 \mathrm{mM}$ sucrose at $\mathrm{pH} 7.2$ ), and the half-thoraces were immediately transferred into fixative (0.1 M sodium phosphate, 3\% paraformaldehyde, 2\% glutaraldehyde, $2 \mathrm{mM}$ sodium EGTA, $0.1 \mathrm{M}$ sucrose at $\mathrm{pH} 7.2$ ) and incubated at $4{ }^{\circ} \mathrm{C}$ overnight on a blood mixer. After $60 \mathrm{~min}$ in wash buffer (0.1 M sodium cacodylate, $0.1 \mathrm{M}$ sucrose at $\mathrm{pH} 7.2$ ), samples were postfixed at room temperature for $60 \mathrm{~min}$ in $1 \%$ osmium tetroxide in wash buffer supplemented with $0.8 \%$ potassium ferrocyanide. Following a further $60 \mathrm{~min}$ in wash buffer, samples were dehydrated through a graded acetone series and then embedded in Spurr resin.

\section{Electrophysiology}

Wandering third instar larvae were dissected in HL3 (Stewart et al. 1994) containing $1.8 \mathrm{mM} \mathrm{CaCl}_{2}$ unless otherwise stated. Nerves innervating the body muscle walls were cut near the ventral ganglion and stimulated using a suction electrode and isolated pulse stimulator Digitimer DS2A /constant current modification), with a current double that needed to initiate a compound response. All recordings were made intracellularly in muscle cell 6 , abdominal segment 2 or 3 , at ambient room temperature $\left(-26^{\circ} \mathrm{C}\right)$, using microelectrodes filled with $3 \mathrm{M} \mathrm{KCl}$ that had tip resistances of 20-30 M $\Omega$. In 1.8 mM extracellular $\mathrm{Ca}^{2+}$, resting membrane potentials were $-71.4 \pm 1.6 \mathrm{mV}(n=20)$ and $-73.5 \pm 1.4 \mathrm{mV}(n=20 ; P>0.05)$ for $a m p h^{+}$and $a m p h^{m u t}$ larvae, respectively. Data were acquired using an Axopatch 200B amplifier, filtered at $1 \mathrm{kHz}$, and digitized at $10 \mathrm{kHz}$ before being stored and analyzed with locally written software (Labview 5.0, National Instruments) and acquired with an AT-MIO-16X DAQ board (National Instruments), or using pClamp8.02 and a Digidata 1320A DAQ board (Axon). Histograms were constructed by averaging 50 separate events stimulated at $1 \mathrm{~Hz}$ from an individual muscle cell and then calculating the mean response from at least 8 larvae per line. In the rundown experiment, temperatures were regulated using a TC-10 temperature controlled stage (Dagan); the permissive temperature used for shibire ${ }^{t s 1}$ recordings was $19^{\circ} \mathrm{C}$, and the restrictive temperature was $32^{\circ} \mathrm{C}$. To facilitate comparisons of data between different cells in the rundown experiment, the first 10 events in a train were averaged and all events were normalized to this value. A mean of normalized evoked responses was made for every 100 stimulations applied to each larva. Spontaneous release events were recorded for $120 \mathrm{sec}$ prior to any electrical stimulation, the first 150 individual nonoverlapping events were measured for each cell, and means from 20 individuals were then averaged to generate the histograms. Mini frequencies were calculated for the full recording period.

\section{Protein expression and binding studies}

Domains of amphiphysin were expressed as $\mathrm{N}$ - or C-terminal GST fusions, expressed in BL-21(DE3) bacteria, and purified on glutathione agarose beads (Sigma). The constructs used were rat-Amph 2-1 N (residues 1-422), rat-Amph 2-6, DrosophilaAmph N (residues 1-357), Drosophila-Amph SH3 (residues 525602), rat-Amph 2 SH3 (residues 494-588 of Amph 2-1), and Drosophila-DAP160 SH3a,b,c,d (Roos and Kelly 1998). The rat amphiphysin splice variants are described in Wigge et al. (1997a). The cloned rat-Amph 2-6 is either identical, or very similar, to the splice form(s) of Amph 2 expressed in muscle. This was determined by comparing the mobilities of the expressed and endogenous proteins on PAGE, and also by sequencing of PCR products from a muscle cDNA library. The muscle form was missing amino acids 336-483, which contain the clathrin-binding motif. Amphiphysin constructs (20 $\mu \mathrm{g}$ of each) were used for affinity interaction experiments (Owen et al. 1998) with tissue extracts (at $\sim 1 \mathrm{mg} / \mathrm{mL}$ ) prepared by homogenization in PBS supplemented with $0.1 \%$ Triton X-100, 1 mM EDTA, and 1: 1000 dilution of protease inhibitor cocktail Set III (Calbiochem). Following SDS-PAGE and transfer onto nitrocellulose, binding partners were assessed by immunoblotting.

\section{Liposome preparation}

Liposomes were prepared as described in Stowell et al. (1999). Folch fraction I lipids (Sigma) were suspended at $1 \mathrm{mg} / \mathrm{mL}$ in 10 
mM HEPES ( $\mathrm{pH} 7.4$ ) and extruded through a 0.1- $\mathrm{\mu m}$ filter. Amphiphysin was added to $\sim 0.1 \mathrm{mg} / \mathrm{mL}$, and lipid binding was terminated after $5 \mathrm{~min}$ by applying $10 \mu \mathrm{L}$ to a carbon-coated 350mesh grid, which was then blotted and stained with $0.5 \%$ uranyl acetate (Stowell et al. 1999).

\section{Acknowledgments}

We thank Janet Powell of the University of Cambridge MultiImaging Centre for EM preparations, and Chris Huang for helpful insights into muscle structure. We also thank Frances Brodsky, Erich Buchner, Gerhard Meissner, Jack Roos, and Dan Woods for antibodies; Reg Kelly and Jack Roos for the GSTDap160 construct; and Daniel Pauli, Paolo d'Avino, the Bloomington Drosophila Stock Center, and the Berkeley Drosophila Genome Project for fly stocks. We are grateful to Chris Doe for support of A. Zelhof's work, and to Kathryn Lilley for facilitating completion of this study. The Cambridge Multi-Imaging Center was established with Wellcome Trust grant 039398/Z/ 93/Z. I.M.R. is an MRC Career Development Award Fellow. This work was supported by Wellcome Trust grant 052625 to N.J.G., A.P.J., and C.J.O'K.

The publication costs of this article were defrayed in part by payment of page charges. This article must therefore be hereby marked "advertisement" in accordance with 18 USC section 1734 solely to indicate this fact.

\section{References}

Atwood, H., Govind, C., and Wu, C. 1993. Differential ultrastructure of synaptic terminals on ventral longitudinal abdominal muscles in Drosophila larvae. J. Neurobiol. 24: $1008-1024$.

Block, B., Leung, A., Campbell, K., and Franzini-Armstrong, C. 1988. Structural evidence for direct interaction between molecular components of the transverse tubule/sarcoplasmic reticulum junction in skeletal muscle. J. Cell Biol. 107: $2587-2600$

Bon, E., Recordon-Navarro, P., and Durrens, P. 2000. A network of proteins around Rvs167p and Rvs161p, two proteins related to the yeast actin cytoskeleton. Yeast 16: 1229-1241.

Brand, A.H. and Perrimon, N. 1993. Targeted gene expression as a means of altering cell fates and generating dominant phenotypes. Development 118: 401-415.

Butler, M.H., David, C., Ochoa, G.-C., Freyberg, Z., Daniell, L., Grabs, D., Cremona, O., and De Camilli, P. 1997. Amphiphysin II (SH3; BIN1), a member of the Amphiphysin/Rvs family, is concentrated in the cortical cytomatrix of axon initial segments and nodes of Ranvier in brain and around T-tubules in skeletal muscle. J. Cell Biol. 137: 1355-1367.

Carozzi, A., Ikonen, E., Lindsay, M., and Parton, R. 2000. Role of cholesterol in developing T-tubules. Analogous mechanisms of T-tubule and caveolae biogenesis. Traffic 1: 326-341.

Crossley, A. 1978. Morphology and development of the Drosophila muscular system. In The genetics and biology of Drosophila, Vol. 2B (eds. M. Ashburner and T. Wright), pp. 499-560. Academic Press, San Francisco, CA.

David, C., McPherson, P.S., Mundigl, O., and de Camilli, P. 1996. A role of amphiphysin in synaptic vesicle endocytosis suggested by its binding to dynamin in nerve terminals. Proc. Natl. Acad. Sci. 93: 331-335.

Delgado, R., Maureira, C., Oliva, C., Kidokoro, Y., and Labarca, P. 2000. Size of vesicle pools, rates of mobilization and recycling at neuromuscular synapses of a Drosophila mutant, shibire. Neuron 28: 941-953.

Dell Angelica, E., Klumperman, J., Stoorvogel, W., and Bonifacio, J. 1998. Association of the AP3 adaptor complex with clathrin. Science 280: 431-434.

Dimitratos, S.D., Woods, D.F., Stathakis, D.G., and Bryant, P.J. 1999. Signaling pathways are focused at specialized regions of the plasma membrane by scaffolding proteins of the MAGUK family. BioEssays 21: 912-921.

Dubois, L., Lecourtois, M., Alexandre, C., Hirst, E., and Vincent, J.-P. 2001. Regulated endocytic routing modulates wingless signaling in Drosophila embryos. Cell 105: 613-624.

Entchev, E.V., Schwabedissen, A., and González-Gaitán, M. 2000. Gradient formation of the TGF- $\beta$ homolog Dpp. Cell 103: 981-991.

Estes, P.S., Roos, J., van der Bliek, A., Kelly, R.B., Krishnan, K.S., and Ramaswami, M. 1996. Traffic of dynamin within individual Drosophila synaptic boutons relative to compartment-specific markers. J. Neurosci. 16: 5443-5456.

Fergestad, T., Davis, W.S., and Broadie, K. 1999. The stoned proteins regulate synaptic vesicle recycling in the presynaptic terminal. J. Neurosci 19: 5847-5860.

Forbes, M.S., Plantholt, B.A., and Sperelakis, N. 1977. Cytochemical staining procedures for sarcotubular systems of muscle: Modifications and applications. J. Ultrastruc. Res. 60: 306-327.

He, J., Conklin, M., Foell, J., Wolff, M., Haworth, R., Coronado, R., and Kamp, T. 2001. Reduction in density of transverse tubules and L-type calcium channels in canine tachycardiainduced heart failure. Cardiovasc. Res. 49: 298-307.

Lahey, T., Gorczyca, M., Jia, X., and Budnik, V. 1994. The Drosophila tumor suppressor gene $D l g$ is required for normal synaptic bouton structure. Neuron 13: 823-825.

Li, J. and Schwarz, T.L. 1999. Genetic evidence for an equilibrium between docked and undocked vesicles. Phil. Trans. $R$. Soc. (London) B Biol. Sci. 354: 299-306.

Liao, G-C., Rehm, E.J., and Rubin, G.M. 2000. Insertion site preferences of the $P$ transposable element in Drosophila melanogaster. Proc. Nat1. Acad. Sci. 97: 3347-3351.

Lichte, B., Veh, R.W., Meyer, H.E., and Kilimann, M.W. 1992. Amphiphysin, a novel protein associated with synaptic vesicles. EMBO J. 11: 2521-2530.

Liu, S.H., Towler, M.C., Chen, E., Chen, C.-Y., Song, W., Apodaca, G., and Brodsky, F.M. 2001. A novel clathrin homolog that co-distributes with cytoskeletal components functions in the trans-Golgi network. EMBO J. 20: 272-284.

MacLennan, D. 2000. $\mathrm{Ca}^{2+}$ signalling and muscle disease. Eur. J. Biochem. 267: 5291-5297.

Mastrogiacomo, A., Parsons, S.M., Zampighi, G.A., Jenden, D.J., Umbach, J.A., and Gundersen, C.B. 1994. Cysteine string proteins: A potential link between synaptic vesicles and presynaptic $\mathrm{Ca}^{2+}$ channels. Science 263: 981-982.

McPherson, P.S., Garcia, E.P., Slepnev, V.I., David, C., Zhang, X., Grabs, D., Sossin, W.S., Bauerfeind, R., Nemoto, Y., and De Camilli, P. 1996. A presynaptic inositol-5-phosphatase. Nature 379: 353-357.

Monck, J., Robinson, I., Escobar, A., Vergar, J., and Fernandez, J.M. 1994. Pulsed laser imaging of rapid $\mathrm{Ca}^{2+}$ gradients in excitable cells. Biophys. J. 67: 505-514.

Munn, A.L., Stevenson, B.J., Geli, M.I., and Riezman, H. 1995. end5, end6 and end7: Mutations that cause actin delocalisation and block the internalisation step of endocytosis in Saccharomyces cerevisiae. Mol. Biol. Cell 6: 1721-1742.

Neufeld, T.P., Tang, A.H., and Rubin, G.M. 1998. A genetic screen to identify components of the sina signaling pathway in Drosophila eye development. Genetics 148: 277-286.

O'Donnell, P.T. and Bernstein, S.I. 1988. Molecular and ultra- 
structural defects in a Drosophila myosin heavy-chain mutant. J. Cell Biol. 107: 2601-2612.

O'Kane, C.J. 1998. Enhancer traps. In Drosophila: A practical approach (ed. D.B. Roberts), pp. 131-178. Oxford University Press, Oxford, UK.

Owen, D.J., Wigge, P., Vallis, Y., Moore, J.D.A., Evans, P.R., and McMahon, H.T. 1998. Crystal structure of the amphiphysin-2 SH3 domain and its role in the prevention of dynamin ring formation. EMBO J. 17: 5273-5285.

Peckham, M., Molloy, J., and Sparrow, J. 1990. Physiological properties of the dorsal longitudinal flight muscle and the tergal depressor of the trochanter muscle of Drosophila melanogaster. J. Muscle Res. Cell. Motil. 11: 203-215.

Pennetta, G. and Pauli, D. 1998. The Drosophila Sin3 gene encodes a widely distributed transcription factor essential for embryonic viability. Dev. Genes Evol. 208: 531-536.

Ramjaun, A.R., Micheva, K.D., Bouchelet, I., and McPherson, P.S. 1997. Identification and characterisation of a nerve terminal-enriched amphiphysin isoform. J. Biol. Chem. 272: 16700-16706.

Ramjaun, A.R., Philie, J., de Heuvel, E., and McPherson, P.S. 1999. The $\mathrm{N}$ terminus of amphiphysin II mediates dimerization and plasma membrane targeting. J. Biol. Chem. 274: 19785-19791.

Razzaq, A., Su, Y., Mehren, J.E., Mizuguchi, K., Jackson, A.P., Gay, N.J., and O'Kane, C.J. 2000. Characterisation of the gene for Drosophila amphiphysin. Gene 241: 167-174.

Reichmuth, C., Becker, S., Benz, M., Debel, K., Reisch, D., Heimbeck, G., Hofbauer, A., Klagges, B., Pflugfelder, G.O., and Buchner, E. 1995. The sap47 gene of Drosophila melanogaster codes for a novel conserved neuronal protein associated with synaptic terminals. Brain Res. Mol. Brain Res. 32: $45-54$.

Robertson, H.M., Preston, C.R., Phillis, R.W., Johnson-Schlitz, D.M., Benz, W.K., and Engels, W.R. 1988. A stable genomic source of $P$ element transposase in Drosophila melanogaster. Genetics 118: 461-470.

Roos, J. and Kelly, R.B. 1998. Dap160, a neural-specific Eps15 homology and multiple SH3 domain-containing protein that interacts with Drosophila dynamin. I. Biol. Chem. 273: 19108-19119.

Sakamuro, D., Elliott, K., Wechsler-Reya, R., and Prendergast, G. 1996. BIN1 is a novel MYC interacting protein with features of a tumour suppressor. Nat. Genet. 14: 66-77.

Scriven, D., Dan, P., and Moore, E. 2000. Distribution of proteins implicated in the excitation-contraction coupling in cardiac myocytes. Biophys. J. 79: 2682-2691.

Seok, J., Xu, L., Kramarcy, N., Sealock, R., and Meissner, G. 1992. The 30-S lobster skeletal muscle $\mathrm{Ca}^{2+}$ release channel (ryanodine receptor) has functional properties distinct from the mammalian channel proteins. J. Biol. Chem. 267: 15893-15901.

Seugnet, L., Simpson, P., and Haenlin, M. 1997. Requirement for dynamin during Notch signaling in Drosophila neurogenesis. Dev. Biol. 192: 585-598.

Shafiq, S. 1964. An electron microscopical study of the innervation and sarcoplasmic reticulum of the fibrillar flight muscle of Drosophila melanogaster. Quart. J. Micro. Sci. 105: 1-6.

Shupliakov, O., Löw, P., Grabs, D., Gad, H., Chen, H., David, C., Takei, K., De Camilli, P., and Brodin, L. 1997. Synaptic vesicle endocytosis impaired by disruption of dynamin-SH3 domain interactions. Science 276: 259-263.

Slepnev, V.I., Ochoa, G.-C., Butler, M.H., Grabs, D., and De Camilli, P. 1998. Role of phosphorylation in regulation of the assembly of endocytic coat complexes. Science 281: 821-824.
Slepnev, V.I., Ochoa, G.C., Butler, M.H., and De Camilli, P. 2000. Tandem arrangement of the clathrin and AP-2 binding domains in amphiphysin I and disruption of clathrin coat function by amphiphysin fragments comprising these sites. J. Biol. Chem. 275: 17583-17589.

Smith, D. 1961. The structure of insect fibrillar muscle. J. Biophys. Biochem. Cyt. (Suppl.) 10: 123-158.

Smith, D.S. and Sacktor, B. 1970. Disposition of membranes and the entry of haemolymph-borne ferritin in flight muscle fibres of the fly Phormia regina. Tissue and Cell 2: 355-374.

Stewart, B., Atwood, H., Renger, J., Wang, J., and Wu, C. 1994. Improved stability of Drosophila larval neuromuscular preparations in haemolymph-like physiological solutions. $J$. Comp. Physiol. A 175: 179-191.

Stimson, D.T., Estes, P., Smith, M., Kelly, L.E., and Ramaswami, M. 1998. A product of the Drosophila stoned locus regulates neurotransmitter release. I. Neurosci. 18: 9638-9649.

Stowell, M.H.B., Marks, B., Wigge, P., and McMahon, H.T. 1999. Nucleotide-dependent conformational changes in dynamin: Evidence for a mechanochemical molecular spring. Nature Cell Biol. 1: 27-32.

Takei, K., Slepnev, V.I., Haucke, V., and De Camilli, P. 1999. Functional partnership between amphiphysin and dynamin in clathrin-mediated endocytosis. Nat. Cell Biol. 1: 33-39.

ter Haar, E., Harrison, S., and Kirchhausen, T. 2000. Peptide-ingroove interactions link target proteins to the $\beta$-propeller of clathrin. Proc. Natl. Acad. Sci. 97: 1096-1100.

Thomas, U., Ebitsch, S., Gorczyca, M., Koh, Y., Hough, C., Woods, D., Gundelfinger, E., and Budnik, V. 2000. Synaptic targeting and localization of Discs-large in a stepwise process controlled by different domains of the protein. Curr. Biol. 10: 1108-1117.

Tuvia, S., Buhusi, M., Davis, L., Reedy, M, and Bennett, V. 1999. Ankyrin-B is required for intracellular sorting of structurally diverse $\mathrm{Ca}^{2+}$ homeostasis proteins. I. Cell Biol. 147: 9951007.

Vallis, Y., Wigge, P., Marks, B., Evans, P.R., and McMahon, H.T. 1999. Importance of the pleckstrin homology domain of dynamin in clathrin-mediated endocytosis. Curr. Biol. 9: 257260.

Vieira, A.V., Lamaze, C., and Schmid, S.L. 1996. Control of EGF receptor signaling via clathrin-mediated endocytosis. Science 274: 2086-2089.

Wechsler-Reya, R., Sakamuro, D., Zhang, J., Duhadaway, J., and Prendergast, G.C. 1997. Structural analysis of the human BIN1 gene. J. Biol. Chem. 272: 31453-31458.

Wigge, P., Köhler, K., Vallis, Y., Doyle, C.A., Owen, D., Hunt, S.P., and McMahon, H.T. 1997a. Amphiphysin heterodimers: Potential role in clathrin-mediated endocytosis. Mol. Biol. Cell 8: 2003-2015.

Wigge, P., Vallis, Y., and McMahon, H.T. 1997b. Inhibition of receptor-mediated endocytosis by the amphiphysin SH3 domain. Curr. Biol. 7: 554-560.

Woods, D., Wu, J., and Bryant, P. 1997. Localization of proteins to the apico-lateral junctions of Drosophila epithelia. Dev. Genet. 20: 111-118.

Zhang, B., Koh, Y.H., Beckstead, R.B., Budnik, V., Ganetzky, B., and Bellen, H.J. 1998. Synaptic vesicle size and number are regulated by a clathrin adaptor protein required for endocytosis. Neuron 21: 1465-1475. 


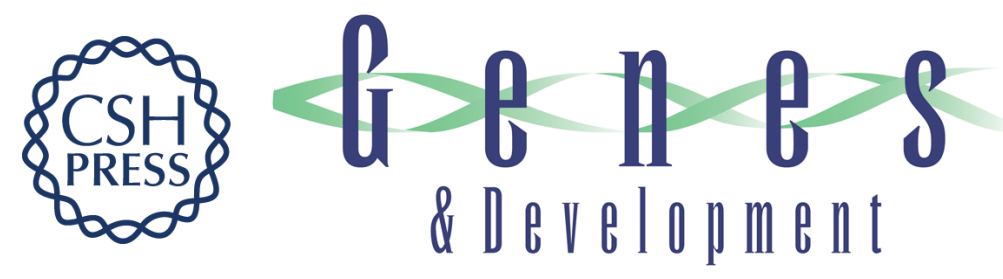

\section{Amphiphysin is necessary for organization of the excitation- contraction coupling machinery of muscles, but not for synaptic vesicle endocytosis in Drosophila}

Azam Razzaq, lain M. Robinson, Harvey T. McMahon, et al.

Genes Dev. 2001, 15:

Access the most recent version at doi:10.1101/gad.207801

References This article cites 58 articles, 27 of which can be accessed free at:

http://genesdev.cshlp.org/content/15/22/2967.full.html\#ref-list-1

License

Email Alerting Receive free email alerts when new articles cite this article - sign up in the box at the top

Service right corner of the article or click here.

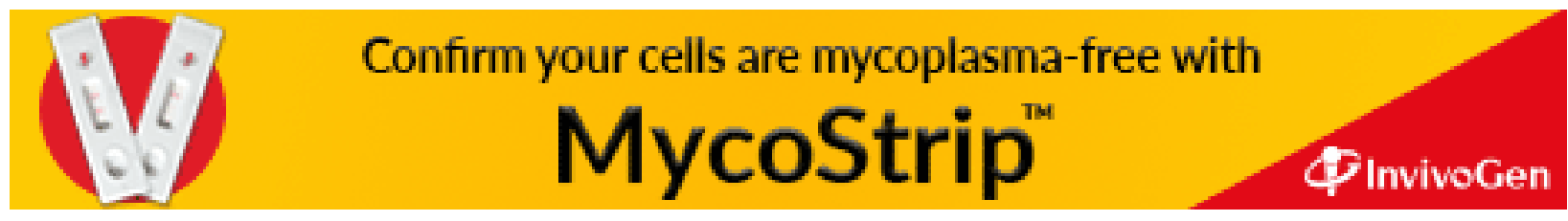

